\title{
Executive function and attention span in euthymic patients with bipolar 1 disorder.
}

\begin{abstract}
This is a cross secti onal co mparison study to assess executive function and attention span in euthymic $\mathrm{p}$ atients with bipolar 1 disorder. It compares the performance of these two cogn itive domains in 40 patients with bipolar 1 disorder to that of 40 healthy normal subjects using Trail Maki ng (TMT), Digit Span (Forward and Backward) and Ver bal Fluency (VF) tests. The association between demographic, clinical characteristics and performance in all tests were examined. Patients wit h bipola $\mathrm{r}$ illness showed significant impairment with moderate to large e ffect siz es $(\mathrm{VF}=0.67$, TMT $\mathrm{A}=0.52$, TMT $\mathrm{B}=0.81$, Digit Forward= 0.97 , Digit ba ckward $=1.10$ ) in all tasks of executive and atte ntion functioning. These impairments a re observed in the absence of active mood symptoms while duration and severity of illness are not found to have an e ffect on both cognitive domains. Medications received by patients with bipolar disorder have significant association with performance on executive tasks. The results of this study add on to the existing global evidence of cognitive impair ment in bipolar illness despite its cross cultural differences. Its presenc e in the absence of mania, depression or mixed episode indicates that cognitive impairmen $t$ is stable even af ter symptoms recovery.
\end{abstract}

Keyword: Attention span; Bipolar 1 disorder; Cognitive impairment; Executive function. 